\title{
Commentary: Nature knows best
}

\author{
Aaron Bettenhausen, MD, and Dawn S. Hui, MD
}

\author{
From the Department of Cardiothoracic Surgery, Long School of Medicine, University of Texas Health Science \\ Center at San Antonio, San Antonio, Tex. \\ Disclosures: Authors have nothing to disclose with regard to commercial support. \\ Received for publication Oct 8, 2019; revisions received Oct 8, 2019; accepted for publication Oct 8, 2019; \\ available ahead of print Oct 24, 2019. \\ Address for reprints: Dawn S. Hui, MD, 7703 Floyd Curl Dr, Suite 211L, San Antonio, TX 78229 (E-mail: dawn. \\ hui@gmail.com). \\ J Thorac Cardiovasc Surg 2021;161:593-4 \\ $0022-5223 / \$ 36.00$ \\ Copyright (c) 2019 by The American Association for Thoracic Surgery \\ https://doi.org/10.1016/j.jtcvs.2019.10.045
}

In this issue of the Journal, Sadri and colleagues ${ }^{1}$ report on the hemodynamic relation of the sinus of Valsalva (SoV) on valve function within a new aortic-valved conduit, by comparing conduits with and without SoV. Using in vitro flow models, the authors demonstrate that the SoV-modeled conduit had greater effective and geometric orifice areas, lower pressure gradients, and lower peak velocities compared with the non-SoV conduit. Moreover, the authors demonstrated that the presence of SoV facilitates the development of larger and more stable vortices during early systole. These vortices in turn resulted in smoother valve closure.

Leonardo da Vinci was possibly the first to appreciate the role of the SoV on aortic valve function, describing the impact of these "semi-ventricles" on creating "room for the surge of the blood," as well as the vortices' impact on valve closure. ${ }^{2}$ Since then, numerous in vitro and in vivo studies have demonstrated the hemodynamic advantage of reconstructing the SoV during aortic root replacement. ${ }^{3-5}$ This article contributes to the body of evidence that preservation or reconstruction of the SoV contributes to the overall function of the aortic valve. Intuitively, with more physiologic hemodynamics and possibly less shear stress, the reconstruction of SoV may lead to longer valve performance. However, large-scale data on the long-term impact on aortic valve function remain lacking.

One limitation of this study is the use of subphysiologic cardiac output in the analysis of valvular function. Although the data presented using a cardiac output of $2.5 \mathrm{~L} / \mathrm{min}$ may offer insight into those patients with low cardiac output, the observed differences in outcomes, although still significant, quickly narrow when more physiological cardiac outputs are considered. Another consideration is the use of acrylic blocks to construct transparent versions of the graft, to facilitate particle imaging velocimetry and high-speed imaging. This choice of material may impact the compliance of the graft and the overall function of the aortic root. Although numerical analysis techniques to investigate cardiovascular biomechanics are rapidly advancing, the problems of

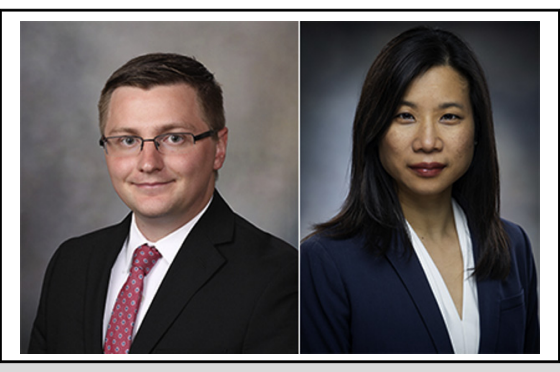

Aaron Bettenhausen, MD, and Dawn S. Hui, MD

Central Message

In vitro testing of a new prosthetic reinforces existing data on the importance of the Sinus of Valsava in aortic root hemodynamics but is subject to model limitations.

See Article page 581 .

modeling fluid-structure interaction are complex ${ }^{6}$ and yet to be routinely incorporated into computational fluid dynamic studies. Comparison of rigid root with compliant root modeling has shown the importance of elasticity, with significant variations in flow rate, valve movement, coaptation area, contact pressure, and closure time. ${ }^{6,7}$ These variations have been demonstrated when comparing native elastic arterial walls, but the elastic properties of graft materials have not yet been defined or studied.

The last several decades have demonstrated a deeper appreciation in preserving the SoV during aortic root surgery. More and more literature expound on our understanding of the complex physiology of the aortic root. Application of the integrated relationship of the SoV and the aortic valve may inform the design of future valvedconduit products. It is just another subtle reminder that nature knows best.

\section{References}

1. Sadri V, Madukauwa-David I, Yoganathan A. In vitro evaluation of a new aortic valved conduit. J Thorac Cardiovasc Surg. 2021;161:581-90.e6.

2. Robicsek F. Leonardo da Vinci and the sinuses of Valsalva. Ann Thorac Surg. 1991;52:328-35.

3. Salica A, Pisani G, Morbiducci U, Scaffa R, Massai D, Audenino A, et al. The combined role of sinuses of Valsalva and flow pulsatility improves energy loss of the aortic valve. Eur J Cardiothoracic Surg. 2016;49:1222-7.

4. Oechtering TH, Hons CF, Sieren M, Hunold P, Hennemuth A, Huellebrand M, et al. Time-resolved 3-dimensional magnetic resonance phase contrast imaging (4D flow MRI) analysis of hemodynamics in valve-sparing aortic root repair with an anatomically shaped sinus prosthesis. J Thorac Cardiovasc Surg. 2016; 152:418-27.

5. Pisani G, Scaffa R, Ieropili O, Dell'Amico EM, Maselli D, Morbiducci U, et al Role of the sinuses of Valsalva on the opening of the aortic valve. J Thoracic Cardiovasc Surg. 2013;145:999-1003. 
6. Marom G, Haj-Ali R, Raanani E, Schäfers HJ, Rosenfeld M. A fluid-structure interaction model of the aortic valve with coaptation and compliant aortic root. Med Biol Eng Comput. 2012;50:173-82.
7. Hsu MC, Kamensky D, Bazilevs Y, Sacks MS, Hughes TJ. Fluid-structure interaction analysis of bioprosthetic heart valves: significance of arterial wall deformation. Comput Mech. 2014;54:1055-71. 